\title{
Synthesis and Properties of Conjugates between Silver Nanoparticles and DNA-PNA Hybrids
}

\author{
Gennady Eidelshtein ${ }^{1}$, Shay Halamish ${ }^{1}$, Irit Lubitz ${ }^{1}$, \\ Marcello Anzola ${ }^{2}$, Clelia Giannini ${ }^{2, *}$ and Alexander Kotlyar ${ }^{1, *}$ \\ ${ }^{1}$ Department of Biochemistry and Molecular Biology, George S. Wise Faculty of \\ Life Sciences and The Center of Nanoscience and Nanotechnology, Tel Aviv \\ University, Ramat Aviv 69978, Israel \\ ${ }^{2}$ Dipartimento di Chimica, Università degli Studi di Milano, via Venezian 21, \\ 20133 Milano Italy \\ *Corresponding authors: s2shak@post.tau.ac.il; clelia.giannini@unimi.it
}

Received 5 October 2012; Accepted 19 November 2012

\begin{abstract}
We describe the preparation and properties of a stable conjugate between two $15 \mathrm{~nm}$ silver nanoparticles (AgNPs) and a DNA-PNA hybrid composed of 10 guanine-cytosine base pairs. We show that the conjugate is spontaneously formed during incubation of a DNA-PNA hybrid, containing phosphorothioate residues at both ends of the DNA strand with AgNPs. The conjugate molecules were separated from individual AgNPs and multiparticle structures by gel electrophoresis. We demonstrate that the absorption spectrum of the conjugate is broader than that of AgNPs, due to the interparticle plasmon coupling.
\end{abstract}

Keywords: Silver nanoparticles, PNA-DNA hybrid, nanomaterials, TEM.

Journal of Self-Assembly and Molecular Electronics, Vol. 1, 69-84.

doi 10.13052/same2245-4551.113

(C) 2013 River Publishers. All rights reserved. 


\section{Introduction}

DNA driven self-assembly of nanoparticles has proved to be useful for the synthesis of novel functional nanomaterials [1]. Relatively simple nanostructures, composed of a small number (2 to 10 ) of nanoparticles connected by DNA [2-7] as well as more complex two- and three-dimensional ones [8, 9] can be fabricated. In addition to unique optical properties, noble metal nanoparticles-DNA conjugates may exhibit electrically conductive or semiconductive behavior and thus, serve as elements in nanoelectronics devices and circuits. Electronic transport measurements on double stranded (ds) DNA molecules have so far yielded very controversial results [10, 11]. Main challenges of direct conductivity measurements are associated with establishing direct physical contact between the DNA and metal electrodes and preserving the native ds conformation of the nucleic acid polymer during conductive measurement under ambient conditions. The environmental factors (e.g. $\mathrm{pH}$, temperature, ionic strength of the medium) greatly affect the stability of the double stranded helix. At low ionic strength the negatively charged strands have a strong tendency to separate from each other. The preparation of samples for direct electrical measurements commonly includes deposition of DNA on electrodes followed by rinsing the surface with distilled water and drying. This treatment can thus lead to the strand separation and, as a result, to a dramatic reduction of the DNA conductivity.

In contrast to dsDNA, stability of PNA-DNA hybrids is independent of ionic strength. PNA (Peptide Nucleic Acid) is a synthetic polymer that composed of nucleic bases connected by peptide bonds [12]. The PNA-DNA hybrid adopts a ds-helical conformation that is very similar with respect to $\pi$ $\pi$ interactions between nucleic bases to a native DNA [13]. PNA is uncharged at neutral $\mathrm{pH}$ unlike DNA, and no repulsion occurs between the complementary strands in dsPNA-DNA hybrids. The absence of interstrand repulsion governs high stability of the hybrids under a wide range of experimental conditions and makes the molecule potentially useful for nanoelectronics.

Here we report synthesis of a PNA-DNA hybrid composed of a PNA strand, $(\mathrm{pG})_{10}$ and a complementary DNA strand, $(\mathrm{dC})_{10}$ as well as preparation of conjugates between the hybrid and $15 \mathrm{~nm}$ AgNPs. Optical properties and molecular morphology of individual conjugates were measured by absorption spectroscopy and transmission electron microscopy (TEM). 


\section{Experimental Procedures}

Unless otherwise stated, reagents were obtained from Sigma-Aldrich (USA).

\subsection{DNA Oligonucleotides}

Cytosine-rich oligonucleotides: [5'-(da) $)_{10}-(\mathrm{dC})_{10}-(\mathrm{da})_{10}$ ], composed of 10 deoxycytidine fragment $(\mathrm{dC})_{10}$ flanked by two runs of phosphorothioated adenosines, $(\mathrm{da})_{10}$ on either side of the strand and $(\mathrm{dC})_{10}$, composed of 10 deoxycytidines, were purchased from Alpha DNA (Canada). These Coligonucleotides were purified on a C8 $4.6 \times 250 \mathrm{~mm}$ (Supelco Inc.) reverse-phase HPLC column. Elution was performed with a linear Methanol gradient from 0 to $50 \%$ in $30 \mathrm{mM} \mathrm{K}-\mathrm{Pi}, \mathrm{pH} 7.5$ for $85 \mathrm{~min}$ at a flow rate of $0.7 \mathrm{~mL} / \mathrm{min}$ at ambient temperature. Chromatography was performed on Agilent 1100 HPLC system. The oligonucleotides eluted from the column were desalted using a pre-packed Sephadex G-25 DNA-Grade column equilibrated with $2 \mathrm{mM}$ Tris-Acetate, $\mathrm{pH}$ 7.5. Quantification of oligonucleotides was done by UV spectrophotometry using extinction coefficients of: 7.4, 15.4 and $11.4 \mathrm{mM}^{-1} \mathrm{~cm}^{-1}$ at $260 \mathrm{~nm}$ for C-, A- and G-bases respectively [14]. Concentration of the $5^{\prime}-(\mathrm{da})_{10^{-}}(\mathrm{dC})_{10}-(\mathrm{da})_{10}$ was quantified, using an extinction coefficient of $382 \mathrm{mM}^{-1} \mathrm{~cm}^{-1}$ at $260 \mathrm{~nm}$.

\subsection{PNA Oligonucleotide}

A PNA strand, containing $10 \mathrm{G}$-bases, a Fluorescein moiety at N-terminus and a $\mathrm{NH}_{2}$ group at $\mathrm{C}$-terminus of the sequence, Flu-(pG) 10 , was synthesized on MBHA resin using a $20 \mu \mathrm{mol}$ scale Boc protocol essentially as described [15]. The synthesis was performed manually in $8 \mathrm{~mL}$ reaction vessel, filled with $100 \mathrm{mg}$ of polystyrene resin beads. The synthetic procedure included 10 Boc deprotection-coupling-washing cycles. The synthesized G-decamer was conjugated with N-Fmoc-6-aminohexanoic (Fmoc-Ahx) pre-activated in a similar manner, and the Fluorescein isothiocyanate was subsequently attached to the N-terminus of Ahx. The kinetics of the PNA-oligomer extension and the conjugation reaction were controlled by ESI and MALDI. The product of the synthesis was purified on a $9.4 \times 250 \mathrm{~mm}$ ZORBAX 300SBC18 reverse-phase HPLC column (Agilent Technologies, USA). The elution was in $0.1 \%$ TFA at a flow rate of $3 \mathrm{~mL} / \mathrm{min}$ with a linear acetonitrile gradient from 5 to $40 \%$. The oligonucleotide was dried by liophylization. The second purification step included ion-exchange HPLC at alkaline $\mathrm{pH}$. The solubility of Flu- $(\mathrm{pG})_{10}$ in aqueous medium at neutral $\mathrm{pH}$ is very low. At alkaline $\mathrm{pH}$ the 
oligonucleotide however becomes highly soluble, as a result of deprotonation of G-bases. Flu-(pG) 10 was dissolved in $0.5 \mathrm{M} \mathrm{LiOH}$ and chromatographed on an anion-exchange HiTrap QHP, $5 \times 1 \mathrm{~mL}$ FPLC column (AmershamBiosciences, USA) in $0.1 \mathrm{M} \mathrm{NaOH}$ containing $10 \%$ acetonitrile. The elution was with linear $\mathrm{NaCl}$ gradient from 0.5 to $1 \mathrm{M}$ at a flow rate of $0.7 \mathrm{~mL} / \mathrm{min}$. The major peak fraction was collected, loaded onto a Sephadex NAP-25 DNA-Grade column, $15 \times 50 \mathrm{~mm}$ (GE Healthcare, USA), equilibrated with 2 $\mathrm{mM}$ Tris-Acetate, $\mathrm{pH} 7.5$ and eluted with the same buffer. The PNA solution was placed into plastic $\left(1.5 \mathrm{~mL}\right.$ capacity) tubes and stored at $4^{\circ} \mathrm{C}$.

\subsection{PNA-DNA Hybrid}

To prepare a ds-Flu-labeled PNA-DNA hybrid, Flu-(pG) $)_{10^{-}}\left[(\mathrm{da})_{10^{-}}(\mathrm{dC})_{10^{-}}\right.$ $\left.(\mathrm{da})_{10}\right]$, HPLC purified Flu-(pG) 10 and $(\mathrm{da})_{10}-(\mathrm{dC})_{10}-(\mathrm{da})_{10}$ were mixed at a $2: 1$ molar ratio in $2 \mathrm{mM}$ Tris-Acetate, $\mathrm{pH} 7.5$. The mixture was heated to $80^{\circ} \mathrm{C}$ for $15 \mathrm{~min}$ and left for 2 to 3 hours at ambient temperature. $\mathrm{NaCl}$ was then added to a final concentration of $100 \mathrm{mM}$. The clear solution turned turbid after 30 min due to precipitation of Flu-(pG) $)_{10}$; the hybrid does not precipitate under these conditions. The sample was then centrifuged in a 5424 Eppendorf bench-top centrifuge at 14,000 rpm for $5 \mathrm{~min}$. The pellet containing Flu$(\mathrm{pG})_{10}$ was discarded and the supernatant, containing the ds-PNA-DNA was transferred to an Eppendorf tube and stored at $4^{\circ} \mathrm{C}$. Concentration of the hybrid was quantified, using an extinction coefficient of $497 \mathrm{mM}^{-1} \mathrm{~cm}^{-1}$ at $260 \mathrm{~nm}$.

\section{$2.415 \mathrm{~nm}$ AgNPs}

$180 \mathrm{~mL}$ of cooled DDW/filtered water were added into a $0.5 \mathrm{~L}$ glass beaker placed in an ice-water bath. $0.45 \mathrm{~mL}$ of $0.1 \mathrm{M} \mathrm{AgNO}_{3}, 0.90 \mathrm{~mL}$ of $50 \mathrm{mM}$ sodium citrate and $0.75 \mathrm{~mL}$ of $0.6 \mathrm{M} \mathrm{NaBH}_{4}$ were consequently added into the beaker under vigorous stirring. The yellow solution was stored at $4^{\circ} \mathrm{C}$ for $12-16$ h. $0.72 \mathrm{~mL}$ of $2.5 \mathrm{M} \mathrm{LiCl}$ were then added under constant stirring at ambient temperature. The solution was transferred into $15 \mathrm{~mL}$ capacity DuPont Pyrex tubes and centrifuged at $14,000 \mathrm{rpm}$ for $1.5 \mathrm{~h}$ at $20^{\circ} \mathrm{C}$ in a Sorval SS-34 rotor. A fluffy pellet was collected. Concentration of AgNPs was estimated spectroscopically using extinction coefficient of $2 \times 10^{9}$ at $400 \mathrm{~nm}$.

Coating of AgNPs with $(\mathrm{dA})_{10}$, an oligonucleotide composed of 10 deoxyadenosines, was conducted as follows: $20 \mu \mathrm{M}(\mathrm{dA})_{10}$ was added to 
$4 \mathrm{~mL}$ of AgNPs (OD 90 at $400 \mathrm{~nm}$ ). $\mathrm{NaCl}$ was then added to a final concentration of $25 \mathrm{mM}$ and the solution was left at ambient temperature for $1 \mathrm{~h}$. The concentration of the salt was increased up to $50 \mathrm{mM}$. One hour later the concentration of $\mathrm{NaCl}$ was adjusted to $100 \mathrm{mM}$, the solution was incubated at ambient temperature for another $80 \mathrm{~min}$ and loaded into a Sepharose 6B-CL column $(1.6 \times 35 \mathrm{~cm})$. Elution was with $10 \mathrm{mM} \mathrm{Na}-\mathrm{Pi}, \mathrm{pH} 7.4$ at ambient temperature. The yellow eluate was collected into $1.5 \mathrm{~mL}$ Eppendorf tubes and centrifuged at 13,000 rpm for $40 \mathrm{~min}$ at RT on bench-top centrifuge 5424 (Eppendorf, Germany). The fluffy pellet was collected and stored in dark at ambient temperature. The resulting nanoparticles were screened for their size and uniformity by TEM, revealing an average diameter of $15 \pm 3 \mathrm{~nm}$. The visible spectra showed a characteristic absorption peak at $400 \mathrm{~nm}$. Concentration of the particles was calculated using an extinction coefficient $(\varepsilon)$ of $2 \times 10^{9} \mathrm{~cm}^{-1}$ at $400 \mathrm{~nm}[16]$.

\subsection{AgNP-DNA-PNA Conjugates}

AgNPs were mixed with Flu- $(\mathrm{pG})_{10}-\left[(\mathrm{da})_{10^{-}}(\mathrm{dC})_{10^{-}}(\mathrm{da})_{10}\right]$ at different molar ratios and incubated for $16 \mathrm{~h}$ in $5 \mathrm{mM} \mathrm{K}-\mathrm{Pi}, \mathrm{pH} 7.5$, containing $100 \mathrm{mM}$ $\mathrm{NaCl}$ at ambient temperature. The incubation mixture was electrophoresed on a $1.5 \%$ agarose gel. The gel areas were cut out from the gel with a razor blade and the conjugates were electroeluted into dialysis bags. Electroeluted samples were centrifuged at $13,000 \mathrm{rpm}$ for $40 \mathrm{~min}$ on a 5424 Eppendorf bench-top centrifuge. The pellets were suspended in a small $(20-100 \mu \mathrm{L})$ volume of TEA buffer.

\subsection{Gel Electrophoresis}

Samples were loaded into a $7 \times 7 \mathrm{~cm} 1.5 \%$ agarose gel, and electrophoresed at $4^{\circ} \mathrm{C}$ and $130 \mathrm{~V}$ for $45 \mathrm{~min}$, using TAE as a running buffer. The gel was stained with ethidium bromide $(5 \mu \mathrm{g} / \mathrm{mL})$ for $20 \mathrm{~min}$. The DNA was visualized with a Bio Imaging System 202D at $302 \mathrm{~nm}$.

\subsection{Absorption Spectroscopy}

Absorption spectra were acquired with a UV/VIS Evolution-60 spectrophotometer from Thermo Scientific (USA). Measurements were conducted at $25^{\circ} \mathrm{C}$ in a wavelength range from 350 to $800 \mathrm{~nm}$. 


\subsection{HPLC}

Chromatography assays were done on Agilent 1100 HPLC system, (Hewlett Packard, USA), including a photodiode array detector unit with quartz flow cells with $1 \mathrm{~cm}$ optical path.

\subsection{TEM Spectroscopy}

TEM images were acquired by using carbon-coated grids (400 mesh). $2.5 \mu \mathrm{L}$ of a sample in $40 \mathrm{mM}$ Tris-Acetate, $\mathrm{pH} 7.8$, were dropped onto a grid surface. After incubation for $5 \mathrm{~min}$ at ambient temperature, the excess solution was removed by blotting with a filter paper. TEM imaging was performed on a TEM (JEM model 1200 EX instrument) operated at an accelerating voltage of $120 \mathrm{kV}$.

\section{Results}

\subsection{Preparation and Characterization of a DNA-PNA Hybrid}

Synthesis of the hybrid includes (see Figure 1): (1) Heating a mixture of HPLC purified PNA and DNA strands (PNA to DNA molar ratio is 2) to $80^{\circ} \mathrm{C}$ and slow cooling the sample down to ambient temperature; (2) addition of $100 \mathrm{mM} \mathrm{NaCl}$, incubation of the mixture at room temperature for an hour and separation of the hybrid from the excess of Flu- $(\mathrm{pG})_{10}$ by centrifugation.

We have shown that the hybrid elutes as a single peak from a sizeexclusion HPLC column (Figure 2A) and is characterized by absorption maxima at 258 and $495 \mathrm{~nm}$ (see inset in Figure 2A). The absorption at 490 and $260 \mathrm{~nm}$ reflects the relative amounts of fluorescein and nucleic bases in the hybrid respectively. The spectrum corresponds nicely with the molecule composed of $10 \mathrm{G}-, 10 \mathrm{C}$-bases and one fluorescein residue. The hybrid migrates through the agarose gel as a single narrow band (Figure 2B). The results presented in Figure 2 thus show that the hybrid is stable and does not dissociate into single strands during HPLC and electrophoresis.

\subsection{Synthesis of Oligonucleotide-Coated Silver Nanoparticles}

The citrate-protected $15 \mathrm{~nm}$ AgNPs are unstable and precipitate out of the solution at salt concentrations higher than $30 \mathrm{mM}$. In order to increase their stability we have coated them with an oligonucleotide composed of 10 deoxyadenines, $(\mathrm{dA})_{10}$. Incubation of AgNPs with large (300-500 fold) molar excess of each of the following sequences: $(\mathrm{dA})_{10},(\mathrm{dC})_{10}$ or $(\mathrm{dG})_{10}$ greatly 


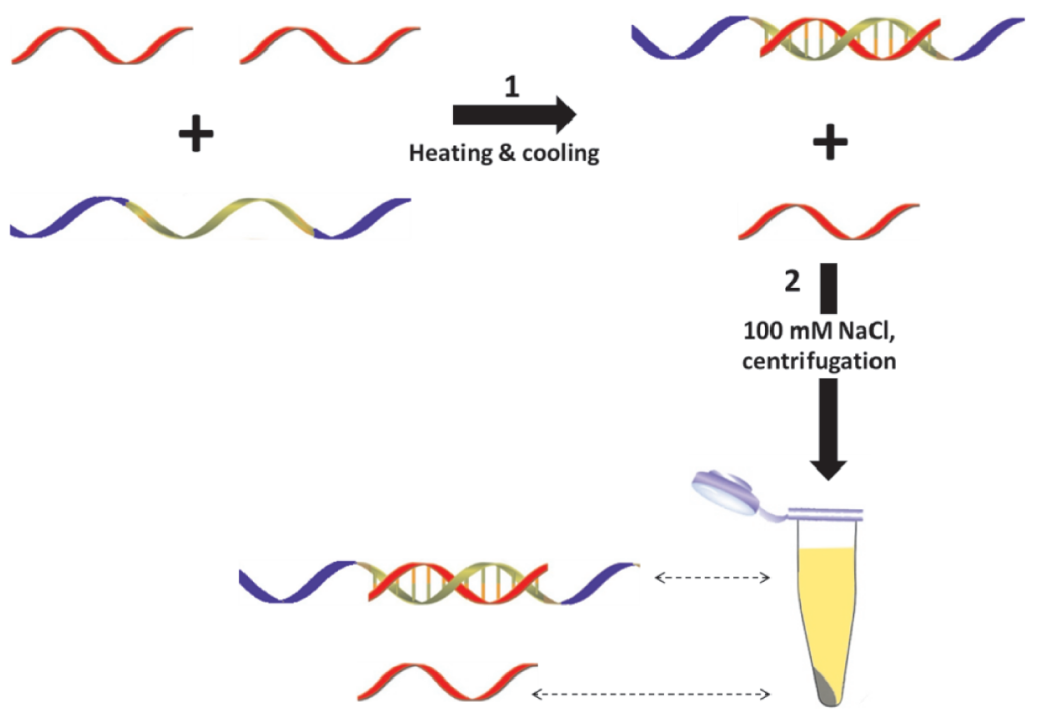

Figure 1 Schematic representation of Flu- $(\mathrm{pG})_{10}-\left[(\mathrm{da})_{10}-(\mathrm{dC})_{10}-(\mathrm{da})_{10}\right]$ synthesis. Flu$(\mathrm{pG})_{10}$ is depicted in red, $\left[(\mathrm{da})_{10}-(\mathrm{dC})_{10}-(\mathrm{da})_{10}\right]$ in green and blue; blue fragments correspond to $(\mathrm{da}) 10$.

increased the resistance of the particles to salts. The above oligonucleotidecoated particles did not precipitate at $100 \mathrm{mM} \mathrm{NaCl}$ in contrast to citrateprotected ones that aggregate at salt concentrations exceeding $30 \mathrm{mM}$. In contrast, $(\mathrm{dT})_{10}$ was incapable of stabilizing the particles.

We have also demonstrated that incubation with ATP did not affect the resistance of citrate-protected AgNPs to salts. The particles coated with $(\mathrm{dA})_{3},(\mathrm{dC})_{3}$ or $(\mathrm{dG})_{3}$ did not aggregate at $50 \mathrm{mM} \mathrm{NaCl}$, but precipitated at higher salt concentrations (data not presented). These results clearly show that stability of nanoparticles depends on the length of oligonucleotide used for coating.

The (dA) ${ }_{10}$-coated particles can be chromatographed and electrophoresed in contrast to citrate-protected ones that do not enter columns and gels. This property enables one to use size-exclusion chromatography (see Section 2) for purification of the particles from high molecular weight aggregates that are always present in the suspension. The size-exclusion chromatography yielded monodisperse spherical nanoparticles with narrow size distribution as revealed by TEM analysis (see Figure 4A). As seen in the TEM image the average size of the particles is equal to $15 \pm 3 \mathrm{~nm}$. 


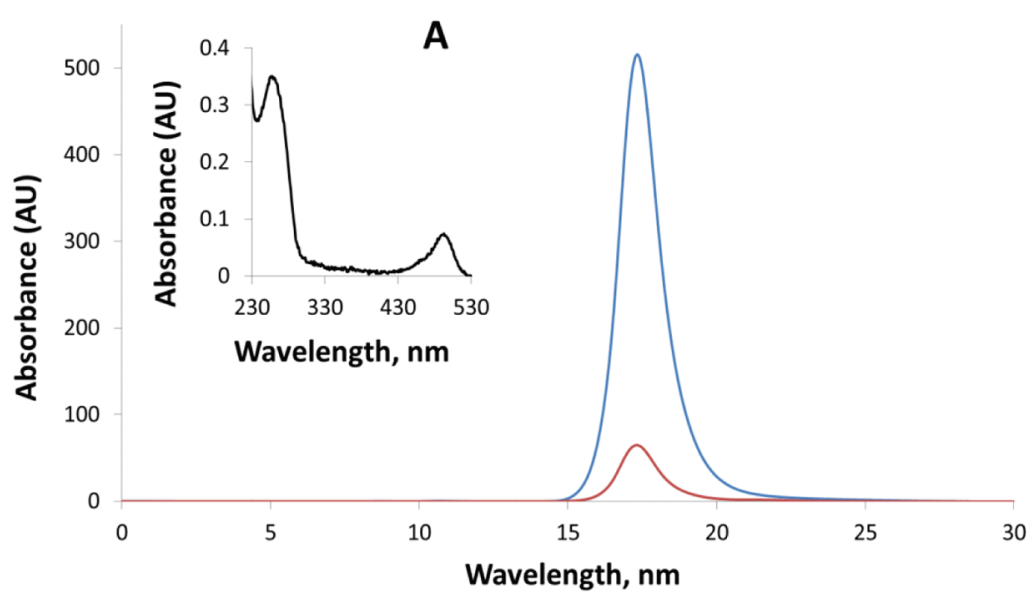

Figure 2 Size-exclusion HPLC (A) and electrophoresis (B) of Flu- $(\mathrm{pG})_{10^{-}}\left[(\mathrm{da})_{10^{-}}(\mathrm{dC})_{10^{-}}\right.$ (da) ${ }_{10}$ ]. The PNA-DNA hybrid was prepared as shown in Figure 1. (A) The hybrid was loaded on a size-exclusion G-4000-DNA-PW HPLC column $(7.8 \times 300 \mathrm{~mm})$ from Toso (Japan) and was isicratically eluted in $20 \mathrm{mM}$ Tris-Acetate, $\mathrm{pH}$ 8.0. The elution was followed at 260 (blue curve) and $495 \mathrm{~nm}$ (red curve). The inset shows a UV/VIS spectrum of the eluted hybrid. (B) $20 \mu \mathrm{L}$ of the hybrid solution were loaded on a $1.5 \%$ agarose gel $(7 \times 7 \mathrm{~cm})$. Electrophoresis was conducted at $4^{\circ} \mathrm{C}$ and $130 \mathrm{~V}$ for $40 \mathrm{~min}$ in TEA buffer. The gel was stained with ethidium bromide.

\subsection{Synthesis of Conjugates between the DNA-PNA Hybrid and AgNPs}

The phosphorothioated residues can covalently anchor the hybrid ends to the surface of silver and gold particles [6, 17], yielding nanoparticle-DNA-PNA conjugates. We have shown that incubation of $(\mathrm{dA})_{10}$-coated AgNPs with the phosphorothioate-functionalized hybrid, $(\mathrm{pG})_{10}-\left[(\mathrm{da})_{10}-(\mathrm{dC})_{10}-(\mathrm{da})_{10}\right]$ as described in Experimental Procedures section yielded structures that move through the gel slower than individual AgNPs. A new yellow band (marked by arrow " 2 ", see lane 3 in Figure 3 ) is clearly seen in the gel image. Incubation of AgNPs with the hybrid not containing phosphorotioated residues, $(\mathrm{pG})_{10^{-}}(\mathrm{dC})_{10}$, under identical conditions did not yield the above band (see Figure 3, lane 2). Slices corresponding to bands "1" and "2" (see Figure 3) were cut out of the gel with a razor blade. The molecules were electroeluted from the slices and characterized by TEM as described in Section 2.

TEM analysis (see Figure 4) shows that the waste majority of structures electroeluted from slices marked with arrows " 1 " and " 2 " composed of 1 and 


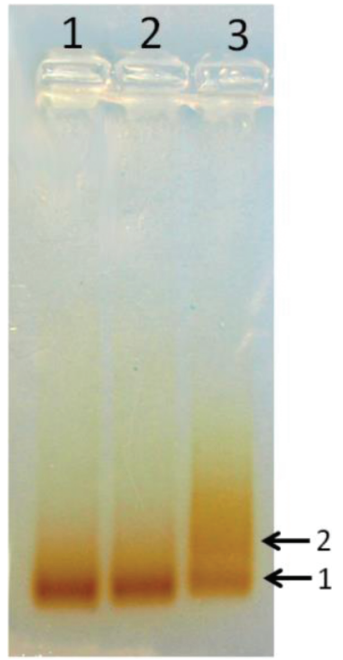

Figure 3 Electrophoretic separation of AgNPs-DNA-PNA conjugates. AgNPs (OD at $400 \mathrm{~nm}$ is equal to 800) (lane 1) were incubated with $0.8 \mu \mathrm{M}(\mathrm{pG})_{10}-(\mathrm{dC})_{10}$ (lane 2) and $0.8 \mu \mathrm{M}$ $(\mathrm{pG})_{10}-\left[(\mathrm{da})_{10}-(\mathrm{dC})_{10}-(\mathrm{da})_{10}\right]$ (lane 3) in: $5 \mathrm{mM} \mathrm{K}-\mathrm{Pi}, \mathrm{pH} 7.5$ and $0.1 \mathrm{M} \mathrm{NaCl}$ at ambient temperature for $24 \mathrm{~h}$. $10 \mu \mathrm{L}$ of each sample was loaded onto a $1.5 \%$ agarose gel and electrophoresed at $4^{\circ} \mathrm{C}$ and $130 \mathrm{~V}$ for $40 \mathrm{~min}$.

2 nanoparticles respectively. Structures electroeluted from the yellow area above band " 2 " (see lane 3 in Figure 4) were composed of 3-4 particles (data not presented). The interparticle separation distance in the conjugates is approximately equal to 3-4 $\mathrm{nm}$ (see inset in the right panel of Figure 4B) that corresponds nicely with the length of a ds-PNA-DNA linker.

As seen in Figure 5 the absorption spectrum of the AgNP-PNA-DNA conjugate is broader than that of the particles not connected to each other. The observed broadening of Ag surface plasmon band around $400 \mathrm{~nm}$ reflects the coupling between closely spaced AgNPs in the structure.

We have shown that the conjugates are stable and do not dissociate into single particles at low ionic strength. Incubation for 2 days at ambient temperature in distillate water produced no effect either on the absorption spectrum or on the mobility of the conjugate band through the gel (data not shown).

\section{Discussion}

We have synthesized a PNA-DNA hybrid composed of a PNA strand, $(\mathrm{pG})_{10}$ and a DNA strand functionalized with phosphorithioated adenine residues on 

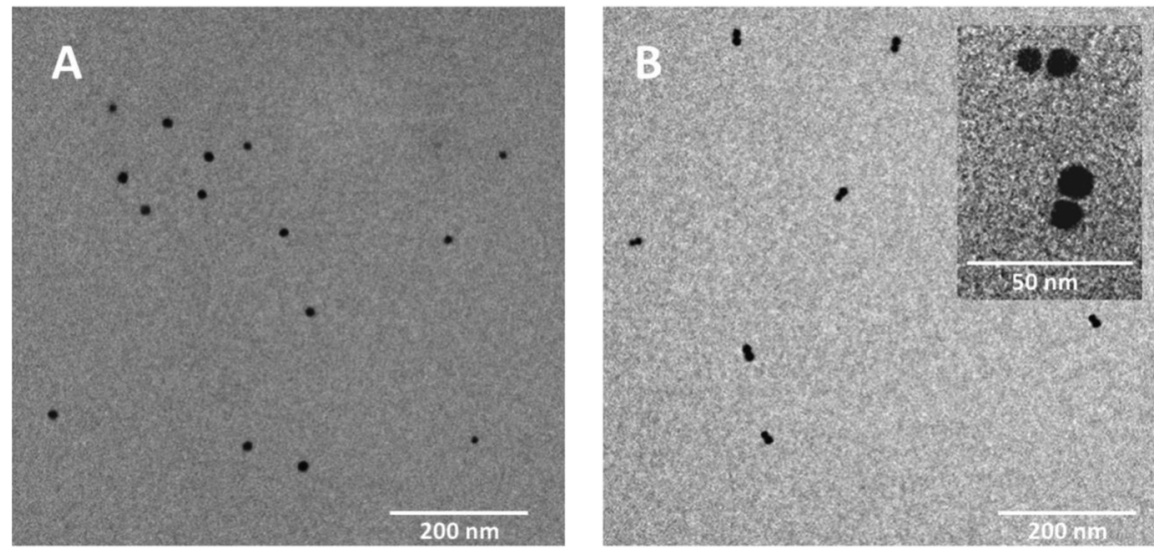

Figure 4 TEM images of AgNPs and the AgNPs-PNA-DNA structures. Molecules electroeluted from gel slices corresponding to bands "1" (A) and "2" (B) (see Figure 3), were deposited on 400 mesh copper carbon grids and visualized by TEM. The inset is an enlarged image of one of the structures.

either side of the DNA oligonucleotide, $(\mathrm{da})_{10^{-}}(\mathrm{dC})_{10^{-}}(\mathrm{da})_{10}$. The hybrid is stable under low ionic strength conditions when the two strands of canonical DNA dissociate from each other.

We have demonstrated that silver nanoparticles in contrast to gold ones can be stabilized by regular adenosine oligonucleotides (not containing thiols, phosphorothioates or amines). Incubation of AgNPs with a great molar excess of oligonucleotides composed of either 10 adenosine, cytosine or guanine bases, yielded stable nanoparticles that do not precipitate at salt concentrations up to $300 \mathrm{mM}$. In contrast, incubation with (dT) $)_{10} 2$ did not affect the particles stability. This result corresponds well with earlier observations, showing that thymine bases interact with the surface of silver [18] and gold $[19,20]$ particles weaker than other DNA bases. The week interaction of thymine thus may due to the absence of an exocyclic amine group in this base.

We have shown (see Figures 4 and 5) that incubation of $(\mathrm{dA})_{10}$-coated AgNPs with PNA-DNA flanked with runs of ten phosphorothioated adeninebases on both ends of the hybrid results in the formation of structures containing two nanoparticles. The absorption spectrum of the dimer is broader than that of AgNPs not connected to each other. It is well known that plasmons of closely spaced nanoparticles are strongly coupled [21, 22]. The spec- 


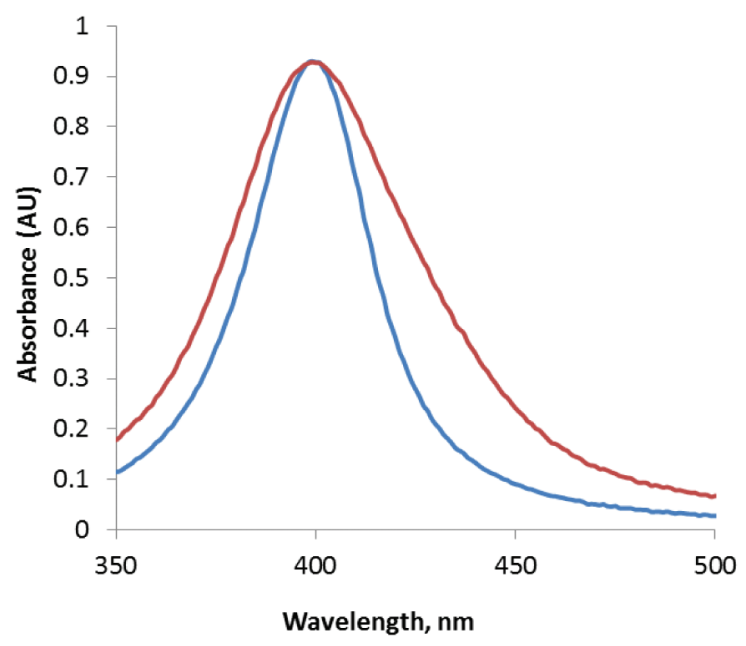

Figure 5 Normalized absorption spectra of AgNPs (blue curve) and AgNP-PNA-DNA conjugates (red curve) electroeluted from a gel slice corresponding to band "2" (see Figure 3).

trum broadening (see Figure 5) thus reflects the presence of electromagnetic coupling between plasmons of AgNPs in the dimer.

The ability of DNA to conduct electrical current depends critically on $\pi$ $\pi$ interaction between stacked Watson-Crick base pairs in the ds-polymer. Even partial strands separation, can strongly reduce, if not completely abolish, conductivity of the DNA molecule. The separation of DNA strands under conditions of low ionic strength might be the reason for poor conductivity reported earlier [23]. PNA-DNA hybrids lack the above disadvantage. The molecule adopts a double helical conformation that is very similar with respect to $\pi-\pi$ interactions to a native ds-DNA even in pure water. Attachment of two $15 \mathrm{~nm}$ silver particles to both ends of the hybrid is also an advantage that makes possible to place the conjugate in between electrodes separated by $20-30 \mathrm{~nm}$ and measure conductivity of very short ( $\sim 3 \mathrm{~nm}$ in our case) DNA-PNA molecules. We believe that conjugates of nanoparticles with PNADNA will possess interesting conductive and optical properties leading to the development of new DNA-based nano-conductors, semiconductors and electro-optical switches. 


\section{Acknowledgments}

This work was supported by the Israel Science Foundation, 172/10. M.A. acknowledges fellowship support from the Nerviano Medical Sciences.

\section{References}

[1] M. R. Jones, K. D. Osberg, R. J. Macfarlane, M. R. Langille, C. A. Mirkin, Chem. Rev., 111, 3736-3827 (2011).

[2] A. P. Alivisatos, K. P. Johnsson , X. G. Peng, T. E. Wilson, C. J. Loweth, M. P. Bruchez, P. G. Schultz, Nature, 382, 609-611 (1996).

[3] C. J. Loweth, W. B. Caldwell, X. G. Peng, A. P. Alivisatos, P. G. Schultz, Chem. Int. Ed., 38, 1808-1812 (1999).

[4] S. Bidault , F. J. G.de Abajo, A. Polman, JACS, 130, 2750-2751 (2008).

[5] A. J. Mastroianni, S. A. Claridge, A. P. Alivisatos, JACS, 131, 8455-8459 (2009).

[6] I. Lubitz, A. Kotlyar, Bioconjug. Chem., 22, 2043-2047 (2011).

[7] N. Borovok, E. Gillon, A. Kotlyar, Bioconjug. Chem., 23, 916-922 (2012).

[8] D. Nykypanchuk, M. M. Maye, D. van der Lelie, O. Gang, Nature, 451, 549-552 (2007).

[9] S. Y. Park, A. K. R. Lytton-Jean, B. Lee S. Weigand, G. C. Schatz, C. A. Mirkin, Nature, 451, 553-556 (2008).

[10] D. Porath, G. Cuniberti, R. Di Felice, Top Curr. Chem., 237, 183-228 (2004).

[11] R. G. Endres, D. L. Cox, R. R. P. Singh, Rev. Mod. Phys., 76, 195-214 (2004).

[12] P. E. Nielsen, M. Egholm, R. H. Berg, O. Buchardt, Science, 254, 1497-1500 (1991).

[13] M. Egholm, O. Buchardt, L. Christensen, C. Behrens, S. M. Freier, D. A. Driver, R. H. Berg, S. K. Kim, B. Norden, P. E. Nielsen, Nature, 365, 566-568 (1993).

[14] C. R. Cantor, M. M. Warshaw, H. Shapiro, Biopolymers, 9, 1059-1077 (1970).

[15] L. Christensen, R. Fitzpatrick, B. Gildea, K. H. Petersen, H. F. Hansen, T. Koch, M. Egholm, O. Buchardt, P. E. Nielsen, J. Pept. Sci., 1, 175-183 (2004).

[16] J. Yguerabide, E. E. Yguerabide, Anal. Biochem., 262, 137-156 (1998).

[17] I. Lubitz, A. Kotlyar, Bioconjug. Chem., 22, 482-487 (2011).

[18] S. Basu, S. Jana, S. Pande, T. Pal, J. Coll. Int. Sci., 321, 288-293 (2008).

[19] A. Gourishankar, S. Shukla, K. N. Ganesh, M. Sastry, J. Am. Chem. Soc, 126, 1318613187 (2004)

[20] L. M. Demers, M. Ostblom, H. Zhang, N. H. Jang, B. Liedberg, C. A. Mirkin, J. Am. Chem. Soc., 124, 11248-11249 (2002).

[21] S. K. Ghosh, T. Pal, Chem. Rev., 107, 4797-4862 (2007).

[22] N. G. Khlebtsov, L. A. Dykman, J. Quantit. Spectrosc. Radiative Transfer, 111, 1-35 (2010).

[23] R. G. Endres, D. L. Cox, R. R. P. Singh, Rev. Mod. Phys., 76, 195-214, (2004). 


\section{Biographies}

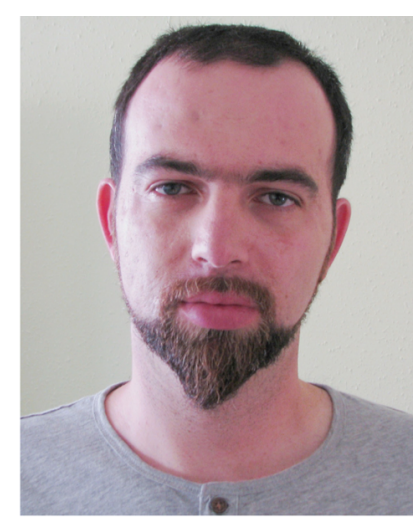

Gennady Eidelshtein received his B.Sc degree in Biotechnology from Hadassah College, Jerusalem, Israel, in 2009. In 2012 Gennady holds his Master's degree in Materials \& Nanotechnology at Tel Aviv University under supervision of Professor Alexander Kotlyar. Today Gennady is Ph.D. student in Alexander Kotlyar's group. His research is focused on novel metal and DNA-based functional nanomaterials.

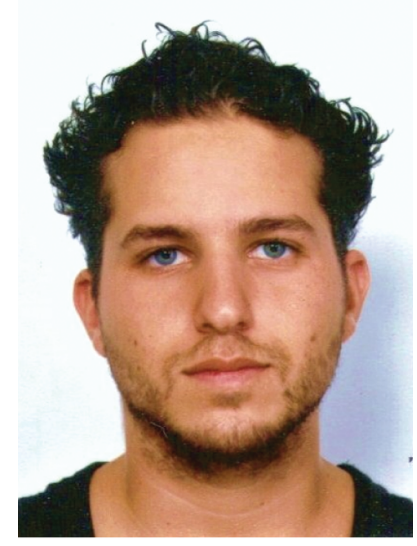

Shay Halamish was born in Jerusalem, Israel, January 1984. He recieved his B.Sc degree in Biotechnology from Bar Ilan University Israel in 2010. In 2010 Shay started his master's degree in Materials \& Nanotechnology at Tel Aviv University under supervision of Professor Alexander Kotlyar. His research is focused on optical properties of metal nanoparticles. 


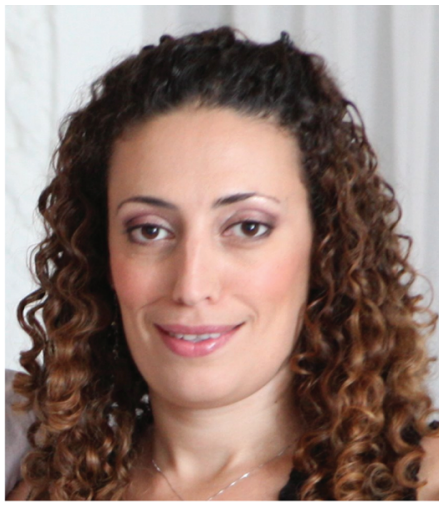

Irit Lubitz was born in Ramat Gan, Israel, January 1977. She received her B.Sc degree in biology from Bar Ilan University, Israel. She holds Master's and Ph.D. degrees in Biochemistry, under supervision of Professor Alexander Kotlyar, from Tel Aviv University. Since 2005 her research has been focused on novel DNA-based functional nanomaterials.

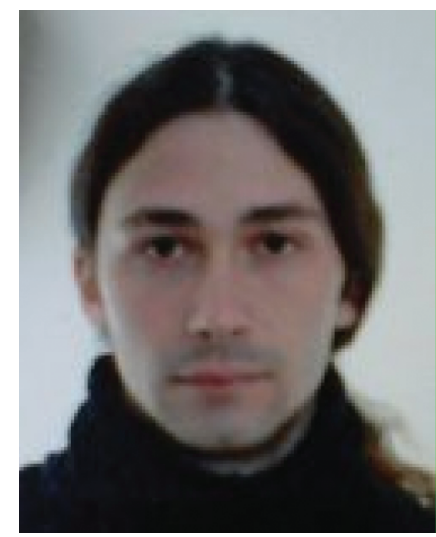

Marcello Anzola was born in Parma, Italy, in 1986. He received his M.Sc degree in Chemistry at Università degli Studi di Parma in 2010. His research was focused on PNAs as diagnostic tools. He currently works at Nerviano Medical Sciences, an Italian research center on oncologic drugs. 


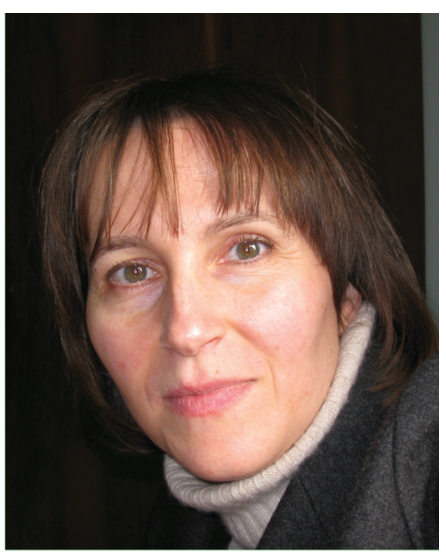

Clelia Giannini graduated in Pharmaceutical Chemistry and Technology in 1996 and received her Ph.D. in Bioactive Natural Compound at University of Naples (Italy) in 2001. She joined, as post-doc, the Organic and Industrial Chemistry Department of University of Milan in 2002. She became Assistant Professor in Organic Chemistry in 2005 at the same university. Her research activity is mostly in the fields of the synthesis and structural studies of modified Peptide Nucleic Acid (PNA).

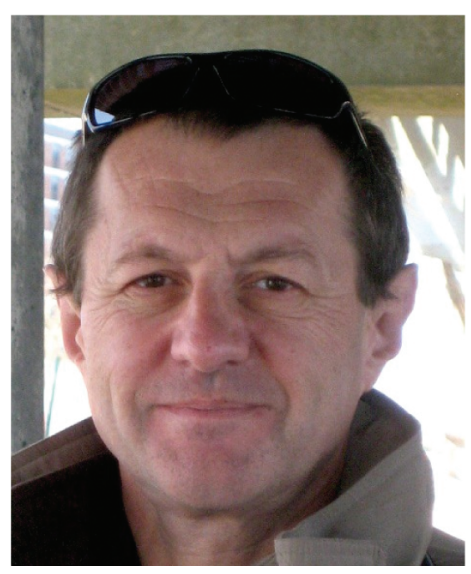

Alexander Kotlyar graduated in Biochemistry and got his Ph.D. in Biochemistry at Moscow State University in 1985. He is a faculty member of Tel Aviv University since 1994 . He is an author of about 100 peer reviewed journal papers. His major research interests since 2001 focus around the DNA- 


\section{G. Eidelshtein et al.}

based nanostructures. He developed novel methods for enzymatic synthesis of various DNA nanowires and complexes of the wires with metal particles. 